\title{
An approach to assess risks of carbon geological storage technology
}

\section{Maísa Matos Paraguassú* and George Câmara}

UFBA, Industrial Engineering Program,

Federal University of Bahia,

Rua Aristides Novis, No. 2, 40.210-630, Salvador, Bahia, Brazil

Email: maisamp6@gmail.com

Email: george@camaraconsultoria.com.br

*Corresponding author

\section{Paulo Sérgio Rocha}

\section{UNIFACS,}

Salvador University - Laureate International Universities, Alameda das Espatódias, 915, 41.820-460, Salvador, Bahia, Brazil Email: psrocha@qgep.com.br

\section{José Célio Silveira Andrade}

UFBA, Faculty of Business Administration, Federal University of Bahia, Av. Reitor Miguel Calmon, s/n, 41.100-903, Salvador, Bahia, Brazil Email: jcelio.andrade@gmail.com

Email: celiosa@ufba.br

\begin{abstract}
Carbon geological storage (CGS) projects are designed to securely store carbon dioxide $\left(\mathrm{CO}_{2}\right)$ for thousands of years. Because of this, there are several studies to evaluate the potential risks of long-term storage of $\mathrm{CO}_{2}$ in geological formations. This paper presents a new method for the qualitative risk assessment of CGS: the risk assessment of stored $\mathrm{CO}_{2}\left(\mathrm{RA}-\mathrm{CO}_{2}\right)$ method. It consists of the systematic and structured identification of $\mathrm{CO}_{2}$ release risk scenarios arising from: seal, well, and fault and fracture zones. The uncertainties associated to each mapped risk scenario and the risks are qualitatively evaluated using the RA- $\mathrm{CO}_{2}$ method. The characteristics of the RA- $\mathrm{CO}_{2}$ method enable a comprehensive understanding of the underground evolution and future behaviour of the $\mathrm{CO}_{2}$ in various time scales and their influence on safety. For future studies, the validation of the proposed $\mathrm{RA}-\mathrm{CO}_{2}$ method using a real case study is recommended.
\end{abstract}

Keywords: risk assessment of stored $\mathrm{CO}_{2} ; \mathrm{RA}-\mathrm{CO}_{2}$ method; qualitative risk assessment; $\mathrm{CO}_{2}$ leakage; $\mathrm{CO}_{2}$ geological storage; $\mathrm{CGS}$.

Reference to this paper should be made as follows: Paraguassú, M.M., Câmara, G., Rocha, P.S. and Andrade, J.C.S. (2015) 'An approach to assess risks of carbon geological storage technology', Int. J. Global Warming, Vol. 7, No. 1, pp.89-109. 
Biographical notes: Maísa Matos Paraguassú received her Master's degree in Industrial Engineering at the Federal University of Bahia (UFBA) in Brazil. She is a Researcher at the Faculty of Business Administration. Her research interests are related to the development of CCS technology on a large scale in Brazil.

George Câmara received his $\mathrm{PhD}$ in Industrial Engineering at the Federal University of Bahia (UFBA) in Brazil. His experience and research interests include the area of energy with emphasis on regulation and climate change, $\mathrm{CO}_{2}$ geological storage, global environmental governance, safety and quality.

Paulo Sérgio Rocha received his $\mathrm{PhD}$ in Petroleum Engineering at the University of Texas, Austin, USA. His experience and research interests include reservoir engineering, enhanced oil recovery, $\mathrm{CO}_{2}$ geological storage, and CCS regulation.

José Célio Silveira Andrade received his $\mathrm{PhD}$ in Business Administration at the Federal University of Bahia (UFBA) in Brazil and his Post-Doctoral in Political Science and International Relations at the Université Laval, Québec, Canada. His research interests include global environmental governance, clean development mechanism, political and institutional strategies, social and environmental strategies and cleaner production.

\section{Introduction}

In recent years, the average temperature of the planet has increased due to the growing concentration of certain gases, called greenhouse gases (GHGs), in the atmosphere that retain heat. The presence of GHGs is important to control the earth's temperature and consequently life on Earth. However, the presence of too many GHGs can cause the temperature to increase uncontrollably and can alter the balance of energy transfers between the atmosphere, space, land, and oceans. Among the GHGs, anthropogenic $\mathrm{CO}_{2}$ emissions are a major contributor to climate change and it made up $77 \%$ of total anthropogenic GHGs emissions between 1970 and 2004. According to the Intergovernmental Panel on Climate Change (IPCC) (2007), carbon dioxide $\left(\mathrm{CO}_{2}\right)$ is the most important of these gases and is taken as a reference.

According to Pacala and Socolow (2004), carbon capture and storage (CCS) technology may bring about a reduction in $\mathrm{CO}_{2}$ of $25 \mathrm{GtC}$ over 50 years. In this context, CCS has been discussed as one within of options to mitigate climate change by authors as, for example, Bachu (2000), IPCC (2005), Viebahn et al. (2007), Gerard and Wilson (2009), Praetorius and Schumacher (2009), Johnsson et al. (2010), and Einsiedel et al. (2013).

The risks of future carbon supply has been strongly debated, as is the viability of alternative energy sources, which do not seem to be able to maintain viability without government financial support ( $\mathrm{Wu}$ et al., 2013). CCS can represent a 'technological bridge' between mitigation of climate change and sustainable energy chain, being an important option against the increase of GHG concentration and, at the same time, allowing the continued use of fossil fuels (Paltrinieri et al., 2013). The CCS life cycle includes steps ranging from the capture of an anthropogenic source of emissions followed by separation, dehydration, compression, transport to storage location and the 
confinement itself. Among the places that have potential for $\mathrm{CO}_{2}$ storage is storage in geological formations (carbon geological storage - CGS), addressed in this work (IPCC, 2005).

According to the International Energy Agency Greenhouse Gas R\&D Programme (IEAGHG, 2009), sedimentary basins have characteristics for safe long-term storage as demonstrated by the existence of natural accumulations of $\mathrm{CO}_{2}$ and by the presence of hydrocarbons trapped in reservoirs. However, due to the characteristics of CGS and the need to guarantee safe storage, risk assessment is a tool that can reveal the main scenarios of risk and identify potential threats and vulnerabilities that may compromise the performance of such systems. This knowledge can provide greater confidence and credibility to the efficiency of storage over hundreds of thousands to millions of years, in other words, on time scales appropriate for geological storage.

Increasingly, many nations and regions are expanding efforts to transition to post fossil carbon societies by changing to renewable energy based on systems, but every production, like every other human activity, involves risks (Wu et al., 2013). Thus, to better understand $\mathrm{CO}_{2}$ leakage risks, the purpose of this paper is to present a new method for CGS qualitative risk assessment, called the risk assessment of stored $\mathrm{CO}_{2}\left(\mathrm{RA}-\mathrm{CO}_{2}\right)$ method, based on the qualitative methods available in the literature. A comparative analysis between the existing methods and the main aspects that influence risk estimate have guided the development of the RA- $\mathrm{CO}_{2}$ method.

\section{Risks in CGS projects}

The history of risk management has evolved since time immemorial. Levantine and Chinese traders prior to A.D. undoubtedly coped with the risk of sailing trade, as the Egyptians and Babylonians did before them. Technology has grown rapidly, a characteristic of our advancing civilisation, which provides many valuable tools, but also introduces new risks ( $\mathrm{Wu}$ and Olson, 2010). The long-term $\mathrm{CO}_{2}$ storage is one of these new technologies that will require a new variety of tools on risk evaluation to support the decision-making with innovative use of analytic techniques.

Risk can be obtained from the 'combination of uncertainty and damage', the 'ratio between hazard and safeguard', and the 'combination of probability and consequence' (Kaplan and Garrick, 1981; Leitch, 2010; Purdy, 2010). The combination of probability (or frequency) and consequence is the most widely used definition of risk. However, as CGS is built into a natural body (a geological formation) risk can be understood as a combination of natural and technological hazards because some causes of possible leaks do not only depend on the operation of technology as usually happens in industrial plants and consequently the causes are not perfectly known or understood (Morgado and Esteves, 2011). Engebø et al. (2013) also bring forward that risks associated with $\mathrm{CO}_{2}$ capture and transport are satisfactorily managed when planned, different from risk related to storage, for which there is no large operational experience.

According to $\mathrm{Wu}$ and Olson (2009), complexity and uncertainty in many practical applications require new methods and tools what are not different for $\mathrm{CO}_{2}$ long-term storage because geophysical and geomechanical changes in the geological formation, the presence of population and the reservoir features may modify the characteristics of $\mathrm{CO}_{2}$ storage and consequently the complexity of risk analysis. For this reason, there is a difficulty of characterising or defining this natural system completely and this is among 
the factors that contribute to risk estimate for the geological storage as well as to uncertainty regarding the site performance (CSLF, ${ }^{1}$ 2009; Condor et al., 2011). The level of uncertainty, which also influence storage risk, is an important factor to estimate $\mathrm{CO}_{2}$ storage capacity and is discussed by Bradshaw et al. (2007), Frailey and Finley (2009), and Szulczewski et al. (2012).

Song and Zhang (2013) discuss the viability of $\mathrm{CO}_{2}$ storage and its long-term safety depends on the sealing capacity and integrity of the cap rock. Koornneef et al. (2012) present the well, the cap rock or seal, and geological faults and fractures as main paths to scenarios that may result in the leakage of $\mathrm{CO}_{2}$ from the target reservoir, shown schematically in Figure 1: wells, cap rock or seal, and geological faults and fractures. In addition, Benson and Hepple (2005) propose some remediation techniques to prevent human or ecosystem impacts. It is noteworthy that, as in risk analysis, the presentation of these remediation options can help build public confidence in CGS Technology.

The risk profile varies over the pre-operation, operation, closure and post-closure phases of the CGS project, as shown in Figure 2. The risks for the CGS project start with the $\mathrm{CO}_{2}$ injection, which begins during the operational phase and continues increasing until the injection starts to reduce or to cease that occurs when the curve flattens. This curve finally tends to decline over time in the closure and post-closure phases, periods corresponding to twice or more the injection period. One of the reasons for the risk increase during operational phase is due to the increase in build-up pressure in the storage reservoir. This pressure starts reducing when the $\mathrm{CO}_{2}$ injection stops because the storage reservoir pressure decreases and trapping measures begin to act over time (Benson, 2008). Kempka et al. (2013) evaluated the contribution of the four $\mathrm{CO}_{2}$ trapping mechanisms (structural, residual, solubility and mineral trapping) to long-term storage at the Ketzin pilot site in Germany. In the risk assessment of Weyburn-Midale, Choi et al. (2013) identified the wellbore integrity as being a significant risk factor for the permanence of long-term $\mathrm{CO}_{2}$ storage, which is associated with corrosion.

Figure 1 Schematic $\mathrm{CO}_{2}$ geological storage site and potential leakage pathways

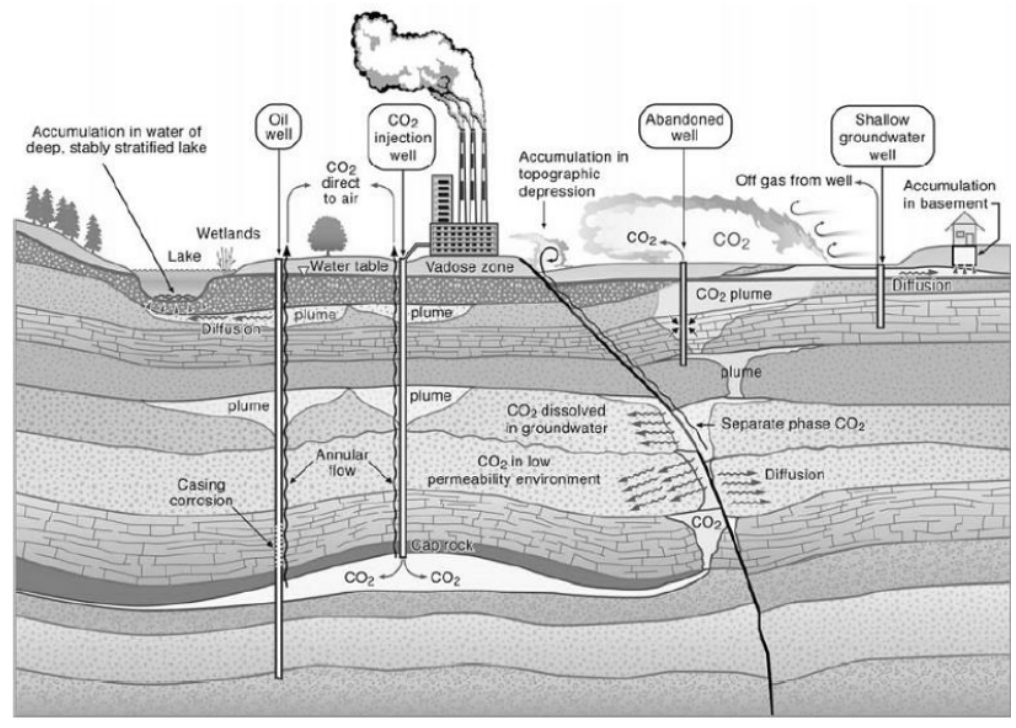

Source: Benson and Hepple (2005) 
Figure 2 Schematic of potential risks during the phases of a hypothetical CGS project

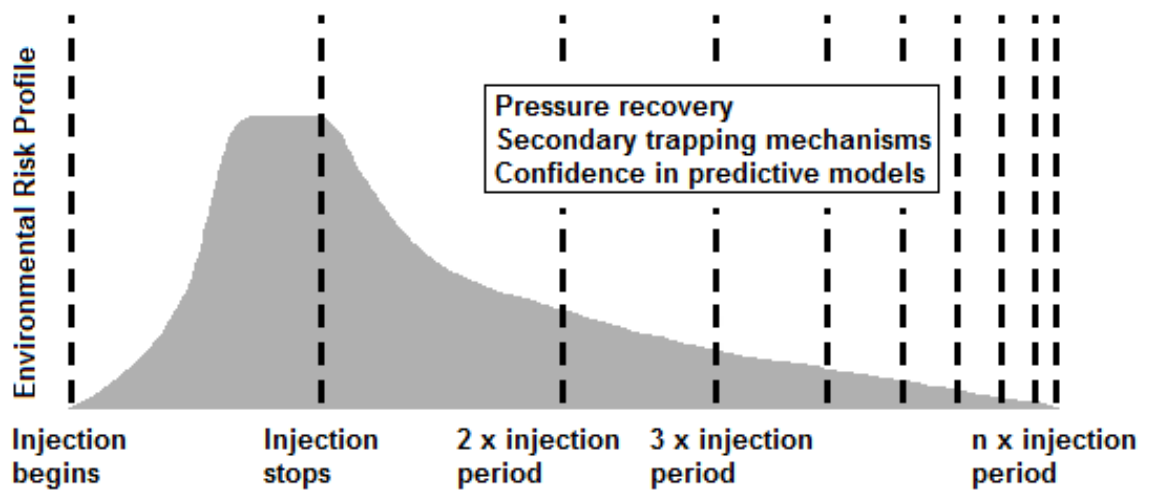

Source: After Benson (2008)

The most critical phase is the operational phase as underground injection of $\mathrm{CO}_{2}$ into porous rock can exceed the allowable formation pressure and consequently can induce fracturing of the cap rock and creating or reactivating geological fractures or faults. This fault activation and induced fracturing by overpressure can create or enhance fracture permeability, thus providing pathways for unwanted $\mathrm{CO}_{2}$. Moreover, during the operational phase problems can occur due to operational errors.

According to Tucker et al. (2013), late in the injection phase, well injection pressures at the sand face could exceed hydrostatic pressure and a combination of temperature and pressure may induce local fractures. The risk assessment shows that there is a possibility of fault reactivation. In addition, potential pathways for migration up to surface could occur along the casing in the case of a failure of the cement bond. For this reason, they emphasise the importance of monitoring tools and techniques with time depending on specific risks. Engebø et al. (2013) discuss the challenges related to risk assessment at each stage in the CCS project.

Although the failure zone of the $\mathrm{CO}_{2}$ storage system suggests low risk, uncertainty regarding the assessment of the risk, if not properly addressed, can presents a bottleneck and one of the greatest challenges for wide scale implementation of CCS (Roberts et al., 2011; Koornneef et al., 2012). In general, there is no historic data available for failure scenarios of $\mathrm{CO}_{2}$ storage and the expert judgement used instead is based on experience in the oil and gas industry, from natural analogue studies and through modelling. Thus, the assessment of failure rates for most of the possible leakage scenarios lacks an empirical base and is heavily dependent on expert judgement. Additionally, there is no methodological standard on whether and how these scenarios should be modelled to estimate the risk using quantitative indicators (Koornneef et al., 2012).

Thus, based on observations of natural and industrial analogues, geological formations can be used to store this gas as long as the site is carefully selected and monitored. The generally adopted probability of leakage and failure through rock and faults is less than that of wellbores. For this reason, wellbores have been important factor associated with the risk of $\mathrm{CO}_{2}$ leakage from the target formation. Among the main concerns are: leaks through completion of poor quality and old injection wells, leaking through abandoned wells and inadequate characterisation of the rock seal as well as 
inconsistent and inappropriate monitoring of injection wells, corrosion coatings (Benson, 2005; CSLF, 2009).

\section{Qualitative risk assessment of CGS projects}

\subsection{Main methods available in literature}

Based on Condor et al. (2011) and NETL (2013), the main qualitative methods for risk assessment of CGS Projects are summarised in Table 1: vulnerability evaluation framework (VEF), structured what-if technique (SWIFT), organised and systemic method of risk analysis (MOSAR), features, events and processes analysis (FEP analysis), carbon storage scenario identification framework (CASSIF), screening and ranking framework (SRF), and multi-criteria assessment (MCA).

Table 1 Qualitative risk methods for CGS projects

\begin{tabular}{|c|c|c|c|}
\hline Method & Objective & Application & References \\
\hline VEF & $\begin{array}{l}\text { Evaluation of the } \\
\text { system's vulnerability to } \\
\text { adverse impacts on the } \\
\text { CGS }\end{array}$ & $\begin{array}{l}\text { Strategy for site } \\
\text { assessment and guide to } \\
\text { regulatory agencies }\end{array}$ & $\mathrm{EPA}^{2}(2008)$ \\
\hline SWIFT & Hazard identification & $\begin{array}{l}\text { Mapping of the dangers } \\
\text { and consequences }\end{array}$ & $\begin{array}{l}\text { Sollie et al. (2011) and } \\
\text { DNV (2010) }\end{array}$ \\
\hline MOSAR & $\begin{array}{l}\text { Identification of the risks } \\
\text { and barriers to contain } \\
\text { them }\end{array}$ & $\begin{array}{l}\text { Systematic analysis of } \\
\text { risk for well-known sites }\end{array}$ & $\begin{array}{l}\text { Cherkaoui and Lopez } \\
\text { (2009) }\end{array}$ \\
\hline FEP & Elaboration of scenarios & $\begin{array}{l}\text { Screening and site } \\
\text { selection }\end{array}$ & $\begin{array}{l}\text { Savage and Maul (2004), } \\
\text { Quintessa (2010), } \\
\text { Wildenborg et al. } \\
(2005), \text { and NETL } \\
(2013)\end{array}$ \\
\hline CASSIF & $\begin{array}{l}\text { Analysis of scenarios } \\
\text { based on the analysis of } \\
\text { well, and seal failures }\end{array}$ & $\begin{array}{l}\text { Screening and site } \\
\text { selection }\end{array}$ & Yavuz et al. (2009) \\
\hline SRF & $\begin{array}{l}\text { Analysis of geological } \\
\text { barriers and potential } \\
\text { leakage near the surface }\end{array}$ & $\begin{array}{l}\text { Risk assessment of } \\
\text { storage sites }\end{array}$ & Oldenburg (2005) \\
\hline MCA & $\begin{array}{l}\text { Evaluation of } \\
\text { alternatives }\end{array}$ & $\begin{array}{l}\text { Strategy for screening } \\
\text { and selecting the storage } \\
\text { location }\end{array}$ & $\begin{array}{l}\text { Gough and Shackley } \\
\qquad(2006)\end{array}$ \\
\hline
\end{tabular}

Source: After Condor et al. (2011)

For a comparative analysis of the risk assessment methods and the aspects influencing the estimated risk each method was evaluated according to how it complied with the following aspects: cause or initiating event, frequency, severity, uncertainty and safeguard. These aspects were selected because of their influence on the estimated risk and the importance of evaluating risk in $\mathrm{CO}_{2}$ storage. 
Each aspect was qualitatively weighted by a team of experts on 4 levels and the methods were classified by numbers from 0 to 3 . A method that received a number 3 classification or considers the aspect analysed through a structured way $100 \%$, while a method that receives a number 2 classification or considers $66 \%$ of the aspect analysed and the methods classified as 1 and 0 consider respectively $33 \%$ and $0 \%$. More detailed information about the weight scales of each method can be found in Paraguassu (2012). The result of this evaluation is presented in Table 2 .

Table 2 Methods evaluated according to compliance with uncertainty, initiator event, safeguard and consequence aspects

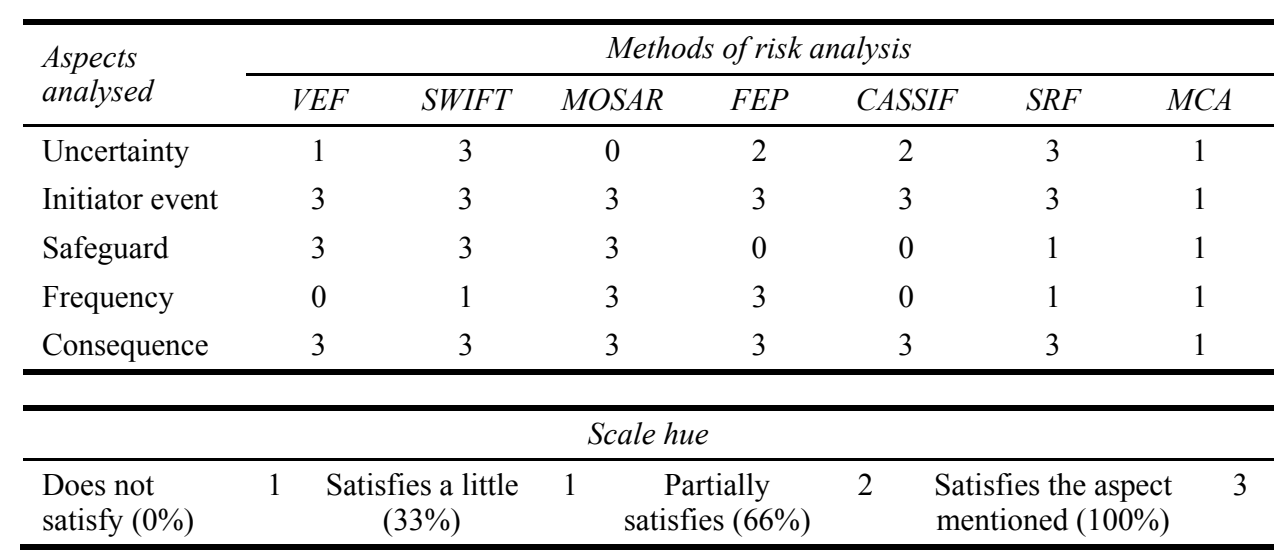

SWIFT is a method for hazard identification based on checklists made from the Quintessa online database. It is used to guide the discussion of topics such as reservoir, seal, overburden, vadose zone, surface, wells, fault zones and atmosphere. The points discussed for each identified hazard are: causes, uncertainty, consequences and safeguards (Sollie et al.; 2011; DNV, 2010). Among the methods for qualitative risk analysis, the SWIFT method was the most structured.

In contrast to the SWIFT method, MCA was the least complete because the items to be analysed by this method depend on the choice of the team executing and the stakeholders because the MCA method allows stakeholders the flexibility to explore options with their own criteria, weightings and scores. Thus, the aspects 'initiating event', 'safeguard', 'uncertainty' and 'frequency' were not presented clearly.

The MOSAR method was structured for understanding the risk scenarios. However, uncertainty, a critical factor for CGS project risk, was not considered. Unlike MOSAR, both the SWIFT and SRF methods considered uncertainty in the analysis. Using SWIFT it is possible to map the uncertainty associated with both frequency and consequence information while in SRF it is possible to map the uncertainty regarding information on HSE risk.

For the CASSIF and FEP methods the uncertainty is dealt with implicitly. In CASSIF, its first step consists of answering a questionnaire in which the user can indicate the level of uncertainty of the quality of site data that will be base for characterising the storage site. While in the FEP Method, uncertainty is associated with the future occurrence of a determined scenario, which is classified as variant scenario.

Despite the importance of measures to prevent, control or mitigate the potential effect of $\mathrm{CO}_{2}$ leakage, the aspect 'safeguard' is not addressed in the most methods. Both the SWIFT and MOSAR methods enable a more structured mapping and VEF indicates 
which items can be evaluated to monitor and mitigate risks. In addition to the 'safeguard' aspect, 'frequency' and 'uncertainty' were aspects poorly treated by the methods due to the lack of specific knowledge based on research and field data that could offer better basis for estimation. Koornneef et al. (2012) discuss these problems. Thus, to deal with all the aspects involved the RA- $\mathrm{CO}_{2}$ Method is proposed as it is flexible, transparent, robust, comprehensive, systematic, low cost and easy to use for qualitative estimation of risk.

\subsection{Background to the $\mathrm{RA}-\mathrm{CO}_{2}$ method}

The criteria and approach used for the development of $\mathrm{RA}-\mathrm{CO}_{2}$ method were defined from the set of characteristics of the qualitative methods of VEF, SWIFT, MOSAR, FEP, CASSIF, and MCA method with the insertion of concepts based on reports and from the sector's leading companies and risk management standards, presented in Table 3.

The structure adopted for the RA- $\mathrm{CO}_{2}$ method, a worksheet with columns, was based on the structure presented by SWIFT and by both hazard and operability study (HAZOP) and preliminary hazard analysis (PHA) methods, which are presented in Bahia (Estado) (2009). The part labelled 'compartment' was based on the term adopted in CASSIF wherein the scenario analysis is performed from the evaluation of three main scenarios leakage of $\mathrm{CO}_{2}$ : well, fault and seal. Polson et al. (2012) also emphasise them as potential leakage pathways.

The part labelled 'aggravating' which is presented in $\mathrm{RA}-\mathrm{CO}_{2}$ method refers to circumstances that can intensity the cause of a particular scenario of $\mathrm{CO}_{2}$ leakage negatively. The 'aggravating' can be classified as dynamic actions and static conditions the main difference between them is their timescales which the static conditions happen on shorter timescales. This approach has been proposed in RA- $\mathrm{CO}_{2}$ method based on FEP Approach to describe the long-term performance and safety of geological storage of $\mathrm{CO}_{2}$.

The analysis of aggravating circumstances is important because the impacts from $\mathrm{CO}_{2}$ leakage depend on the response of local organisms to elevated $\mathrm{CO}_{2}$ concentrations, which can be long-term chronic and short-term acute exposure as discussed by Koornneef et al. (2012), who also emphasise the effect of long-term exposure on ecosystems as a knowledge gap. For healthy humans, some effects are presented in IPCC (2005).

The proposed criteria for the both frequency and severity categories were also based on Bowden et al. (2013a, 2013b) and on the industrial risk analysis guide (FEPAM, 2001), risk assessment tool and guidance (HSE 2008) and the standard risk management of Bahia [Bahia (Estado), 2009], and Australian Standards (2004) strongly cited by Fletcher (2005) and Underschultz et al. (2011). Despite the references FEPAM (2001), HSE (2008) and Bahia (Estado (2009) are not specific to the risk of $\mathrm{CO}_{2}$ storage, they are consolidated technical risk references. In order to be consistent with ISO 31000 (2009), the study was conducted following its guidelines.

The mapping of the uncertainty of frequency and severity in the RA-CO $\mathrm{O}_{2}$ method was adopted based on SWIFT, CASSIF, FEP and SRF methods. Although these methods handle uncertainty in different ways, the mapping of the uncertainty is an important point in the RA- $\mathrm{CO}_{2}$ method because it is one of the greatest challenges for CCS projects as discussed by authors as Condor et al. (2011), Koornneef et al. (2012), Roberts et al. (2011), Polson et al. (2012). 
Table 3 References for the development of the RA- $\mathrm{CO}_{2}$ method

\begin{tabular}{|c|c|c|}
\hline $\begin{array}{l}\text { Items of the } \\
\text { proposed } \\
\text { method }\end{array}$ & Brief definition & References \\
\hline Compartment & $\begin{array}{l}\text { Main migration paths for leakage of } \\
\qquad \mathrm{CO}_{2}\end{array}$ & $\begin{array}{c}\text { Cherkaoui and Lopez (2009), Bahia } \\
\text { (Estado) (2009), Wildenborg et al. } \\
\text { (2005), and Yavuz et al. (2009) }\end{array}$ \\
\hline Attenuating & $\begin{array}{l}\text { Also called 'Safeguards' they are } \\
\text { measures and actions that can reduce } \\
\text { risk }\end{array}$ & $\begin{array}{l}\text { Cherkaoui and Lopez (2009), Bahia } \\
\text { (Estado) (2009), Wildenborg et al. } \\
\text { (2005), Yavuz et al. (2009), DNV } \\
\text { (2010), and Sollie et al. (2011) }\end{array}$ \\
\hline Aggravating & $\begin{array}{l}\text { Items that may intensify the event } \\
\text { initiator or the effects of } \mathrm{CO}_{2} \\
\text { leakage }\end{array}$ & Wildenborg et al. (2005). \\
\hline Frequency & Chance of $\mathrm{CO}_{2}$ leakage occurring & $\begin{array}{l}\text { FEPAM (2001), Cherkaoui and } \\
\text { Lopez (2009), Bahia (Estado) } \\
\text { (2009), DNV (2010), and Sollie } \\
\text { et al. (2011) }\end{array}$ \\
\hline Severity & $\begin{array}{l}\text { Consequence or impact categories } \\
\text { due to } \mathrm{CO}_{2} \text { leakage }\end{array}$ & $\begin{array}{l}\text { Wildenborg et al. (2005), HSE } \\
\text { (2008), Cherkaoui and Lopez } \\
\text { (2009), Bahia (Estado) (2009), and } \\
\text { Yavuz et al. (2009) }\end{array}$ \\
\hline $\begin{array}{l}\text { Cause or } \\
\text { initiator event }\end{array}$ & $\begin{array}{c}\text { Each event initiator can have one or } \\
\text { more causes responsible for the } \\
\text { occurrence of leakage }\end{array}$ & $\begin{array}{l}\text { Wildenborg et al. (2005), EPA } \\
\text { (2008), Cherkaoui and Lopez } \\
\text { (2009), Bahia (Estado) (2009), DNV } \\
\text { (2010), and Sollie et al. (2011) }\end{array}$ \\
\hline Uncertainty & $\begin{array}{l}\text { Level of mistrust or doubt about the } \\
\text { information provided during the } \\
\text { analysis }\end{array}$ & $\begin{array}{l}\text { Oldenburg (2008), Yavuz et al. } \\
\text { (2009), DNV (2010), and Sollie } \\
\text { et al. (2011) }\end{array}$ \\
\hline
\end{tabular}

Paté-Cornell (1996), for example, presents different levels of uncertainty treatment in risk analysis mainly from a quantitative viewpoint. However, for the purposes of the RA- $\mathrm{CO}_{2}$ method uncertainty is qualitatively weighted on a scale of 0 to $100 \%$ to assess the quality of information given and to qualify the scenario uncertainty by the team that leads to risk analysis from the RA- $\mathrm{CO}_{2}$ method. This weighted scale is proposed based on Oldenburg (2005), Sollie et al. (2011), Polson et al. (2012), Bowden et al. (2013a, 2013b).

The risks are grouped into categories according to severity to people, environment, image, facilities (geological storage) and financial aspects. These categories were adopted based on Australian Standards (2004), HSE (2008), Bahia (Estado) (2009) and DNV $(2009,2010,2011)$ and the criteria for frequency category based on FEPAM (2001) and Bahia (Estado) (2009).

\section{RA-CO 2 method: a new approach to assess CGS risks}

The RA- $\mathrm{CO}_{2}$ method is a qualitative method for risk assessment of CGS technology. The RA- $\mathrm{CO}_{2}$ method has been developed to analyse the ways in which $\mathrm{CO}_{2}$ can be released in an undesirable or uncontrolled fashion and consequently lead to potential impacts such as 
damage to the company reputation or project image, environment, personal security, integrity of the storage system and financial damage. The risks are qualitatively evaluated and classified as high, medium or low risk.

\section{$4.1 \mathrm{RA}-\mathrm{CO}_{2}$ method implementation}

\subsubsection{Teamwork approach}

The RA- $\mathrm{CO}_{2}$ method is an inductive method structured to identify the potential causes that can lead to the danger of $\mathrm{CO}_{2}$ leakage from the storage site and the results of this method depend on available information and on team experience. Thus, a multidisciplinary team should perform the analysis. The presence of at least three types of professionals in the team is essential to support the analysis: a leader, a supporter (scribe, data recorder, organiser, etc.), and an expert. The leader is the person who knows the method and is responsible for carrying out the risk analysis, the scribe records the information and the expert has information and knowledge of similar systems (Sutton, 1997; Nolan, 1994).

\subsubsection{Database and information for identifying risks}

Good quality information is important in identifying risks and the starting point for risk identification may be historical records, incident databases and analysis of failures and previous risk registers if they exist. There are also focus group discussions, surveys and questionnaires, structured interviews, expert judgement and personal experience or past organisational experience, results and reports from audits, inspections and site visits, checklists (Australian Standards, 2004). A database that has often been used is FEP Database developed by Quintessa (2010) which contains FEPs that describe the current and future states of the storage system.

Some typical data used to characterise and select geological $\mathrm{CO}_{2}$ storage sites are presented by IPCC (2005): seismic profiles across the area of interest, structure contour maps of reservoirs and seals, maps of the structural boundaries of the trap, documentation and maps of faults and fault, oil and gas production data, geomorphological data and tectonic investigations.

\subsection{3 $\mathrm{RA}-\mathrm{CO}_{2}$ method review steps}

Once the boundary conditions are determined, defining the objectives and scope of the analysis as well as the participants of the working team and survey data required for analysis, the next step is defining the boundaries of the process analysis from a subdivision into compartments. Then, from the system data and team experience, the worksheet presented in Table 4 is completed. The conceptual model of the RA- $\mathrm{CO}_{2}$ Method can be seen in Figure 3 showing the implementation steps.

For each cause or initiator event identified the potential impacts, attenuating (safeguards) and aggravating factors are mapped, the frequency of occurrence and severity are associated: the basis for risk scenario formation. The simplified sequence of steps used to conduct the review is as follows:

- define the objectives and scope of the analysis

- define the teamwork and boundary conditions 
- $\quad$ perform data collection

- $\quad$ explain the RA-method and the design intentions (workshop/meeting)

- identify the scenario causes (initiator events) and consequences

- identify all attenuating and aggravating factors that influence the evolution states of $\mathrm{CO}_{2}$ storage

- $\quad$ specify the attenuating factors (safeguards)

- determine the frequency of occurrence and severity of each scenario

- $\quad$ ponder the uncertainty associated to frequency of occurrence and severity of each scenario

- for the risks classified as unacceptable, make recommendations to reduce it, ranking all recommendations according to schedule of implementation

- $\quad$ write the final report.

Figure 3 Conceptual model of the $\mathrm{RA}-\mathrm{CO}_{2}$ method

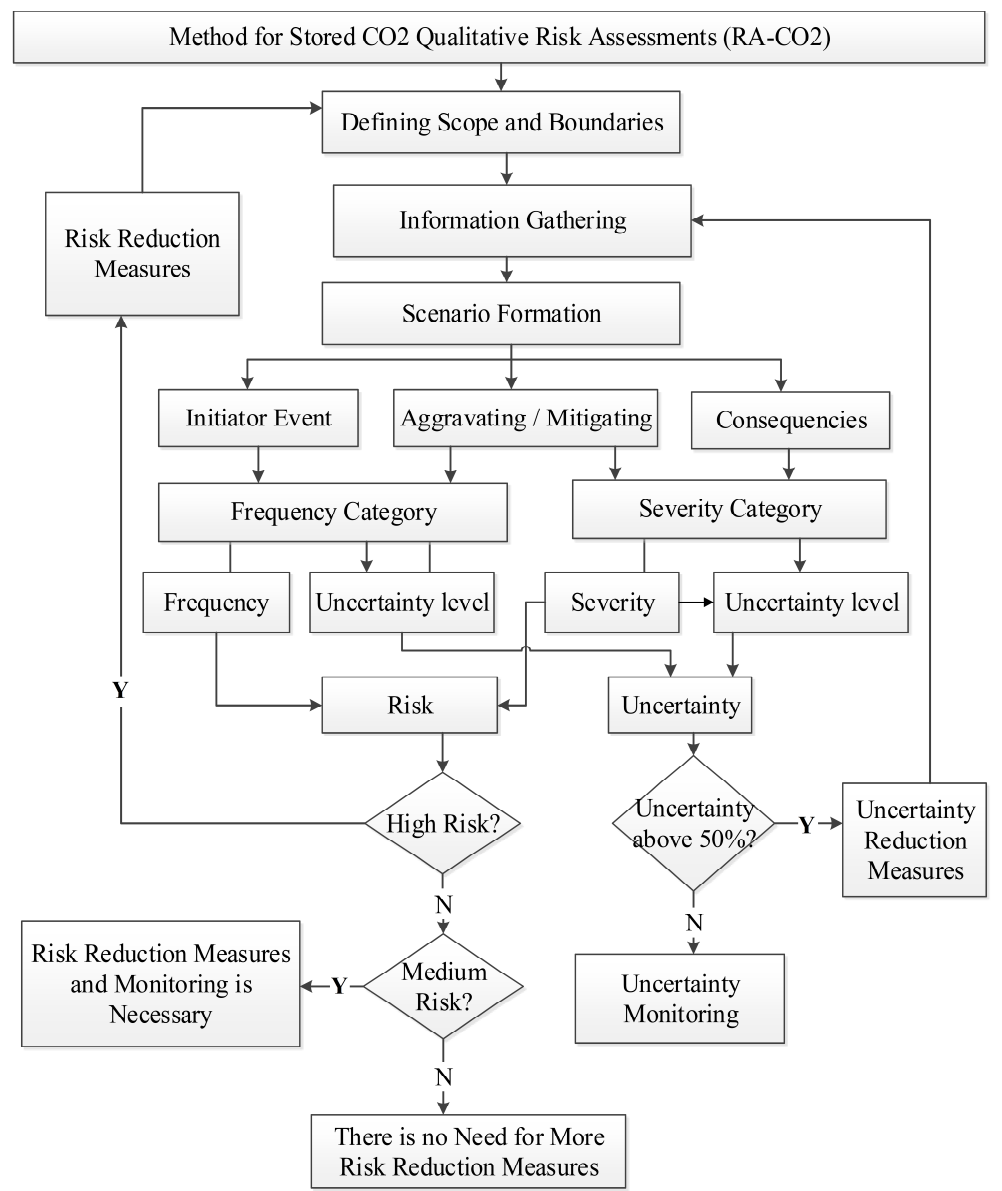


Table 4 Worksheet example for the method for stored $\mathrm{CO}_{2}$ qualitative risk assessments $\left(\mathrm{RA}-\mathrm{CO}_{2}\right)$

\begin{tabular}{|c|c|c|c|c|c|c|c|c|c|c|c|c|}
\hline \multicolumn{13}{|c|}{ Method for stored $\mathrm{CO}_{2}$ qualitative risk assessments $\left(\mathrm{RA}-\mathrm{CO}_{2}\right)$} \\
\hline $\begin{array}{l}\text { Comp } \\
\text { Team } \\
\end{array}$ & $\begin{array}{l}\text { partmen } \\
\text { ?: }\end{array}$ & & & & & & \multicolumn{2}{|c|}{$\begin{array}{l}\text { System/area: } \\
\text { Date: }\end{array}$} & \multicolumn{4}{|c|}{ Page: } \\
\hline \multicolumn{5}{|c|}{ Aggravating } & \multicolumn{2}{|c|}{$\begin{array}{c}\text { Frequency } \\
\text { category }\end{array}$} & \multicolumn{2}{|c|}{$\begin{array}{l}\text { Severity } \\
\text { category }\end{array}$} & \multicolumn{4}{|c|}{ Risk category } \\
\hline 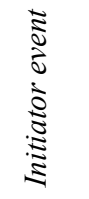 & 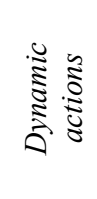 & 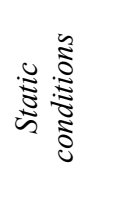 & 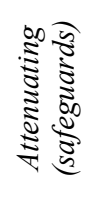 & 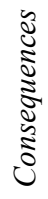 & 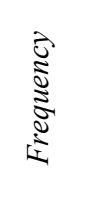 & 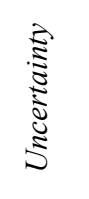 & 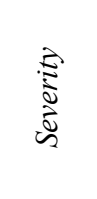 & 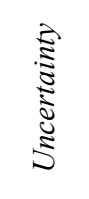 & 该 & 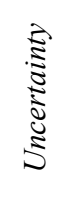 & 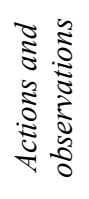 & 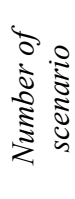 \\
\hline 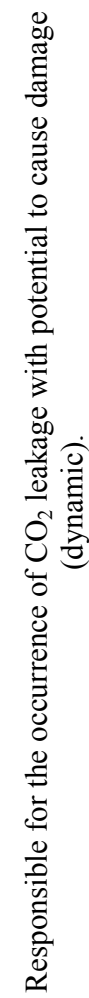 & 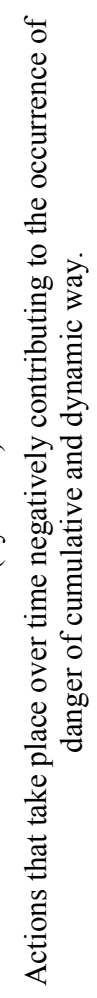 & 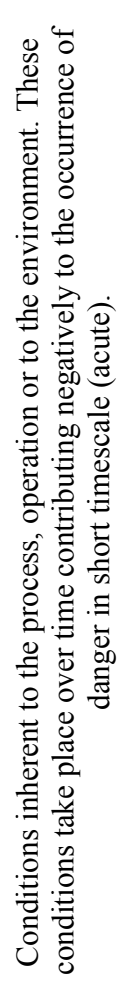 & 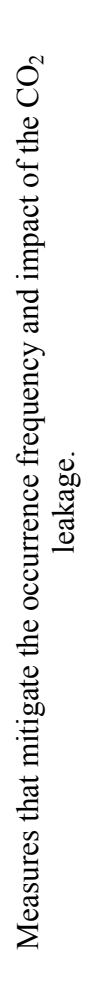 & 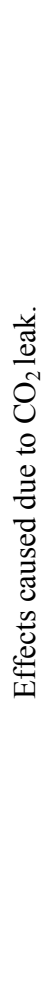 & 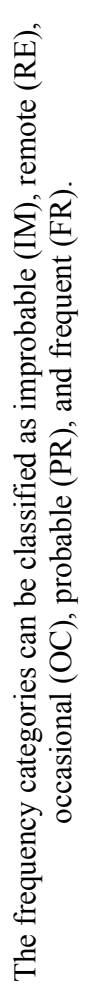 & 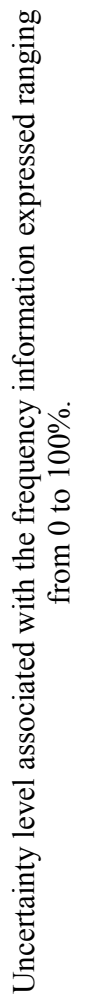 & 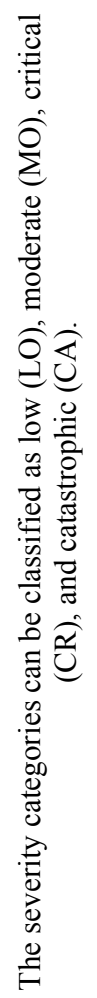 & 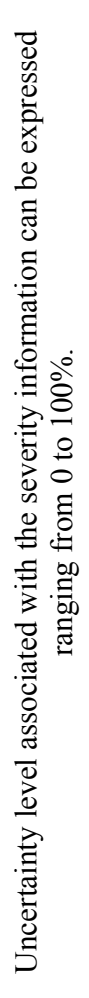 & 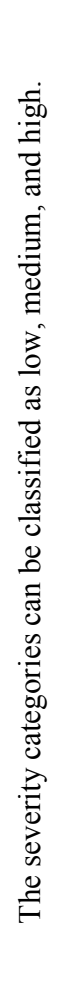 & 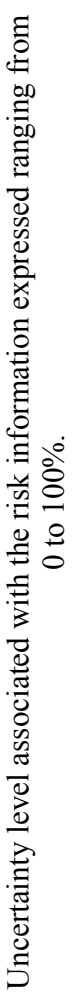 & 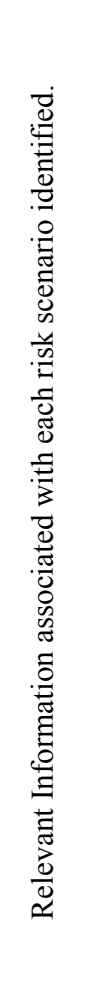 & 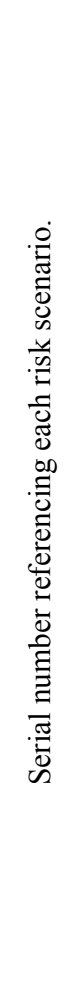 \\
\hline
\end{tabular}

\subsection{Structure of $\mathrm{RA}-\mathrm{CO}_{2}$ method}

The RA- $\mathrm{CO}_{2}$ method worksheet is basically structured in nine main columns for initiator events, aggravating circumstances, mitigating measures, consequences from $\mathrm{CO}_{2}$ leakage, frequency and severity categories, suggestions or recommendations and one number column to reference each accident scenario as shown in Table 4 and described as follows:

(1st column) initiator event: In this column all initiating events or causes which may lead to the unwanted migration of $\mathrm{CO}_{2}$ impacting the company reputation, project image, 
environment, people's safety and causing financial damage are listed. The causes or initiator events of $\mathrm{CO}_{2}$ leakage may involve both human errors and natural occurrences.

(2nd column) aggravating: in this column, the actions and conditions that may contribute negatively to increase the occurrence of initiating events or leveraging the events identified are listed. The aggravating circumstances can be due to static conditions or dynamic actions.

Static conditions are conditions inherent to the process, operation or environment. The result for the event initiator is immediate (acute) and for this reason its timescale is smaller compared to the dynamic action timescale. Dynamic actions are actions that happen over time and the outcomes of the initiator event are cumulative and dynamic because the effect from the action is not immediate. Therefore, dynamic actions are chronic actions.

(3rd column) attenuating (safeguards): in this column, the preventive or corrective measures to avoid $\mathrm{CO}_{2}$ leakage scenarios developing into incidents and mitigate its effects are described. Also called 'safeguard', the preventing and mitigating measures are actions that may reduce the both occurrence frequency and severity of the analysed risk scenarios and depending on the case may also reduce uncertainty associated with the frequency and consequence.

(4th column) consequences: in this column the consequences of the effect expected as result of the identified initiator event are described. These consequences are related to the impact and effects that can lead to financial losses, put at risk people's safety, the company reputation or project image, environment and storage system facilities.

(5th column) frequency: in this column the frequency category of scenarios and their level of uncertainty are shown. The degree of uncertainty associated with the frequency information is expressed as a percentage ranging from 0 to $100 \%$ depending on the consensus of the executing team. The frequency categories can be classified as improbable (IM), remote (RE), occasional (OC), probable (PR), and frequent (FR) as presented in Table 5.

Table 5 Example of frequency categories for $\mathrm{RA}-\mathrm{CO}_{2}$ method

\begin{tabular}{ccc}
\hline Sigla & Name & Description \\
\hline IM & Improbable & Conceptually possible, but extremely unlikely to occur during the lifetime \\
of the project.
\end{tabular}

(6th column) severity: in this column the severity category of the scenario and its level of uncertainty associated to frequency information are shown. The degree of uncertainty associated with the frequency information is expressed as a percentage ranging from 0 to $100 \%$ depending on the consensus of the executing team. The severity categories can be classified as low (LO), moderate (MO), critical (CR), and catastrophic (CA) as presented in Table 6. 
Table 6 Example of the severity categories for RA- $\mathrm{CO}_{2}$ method

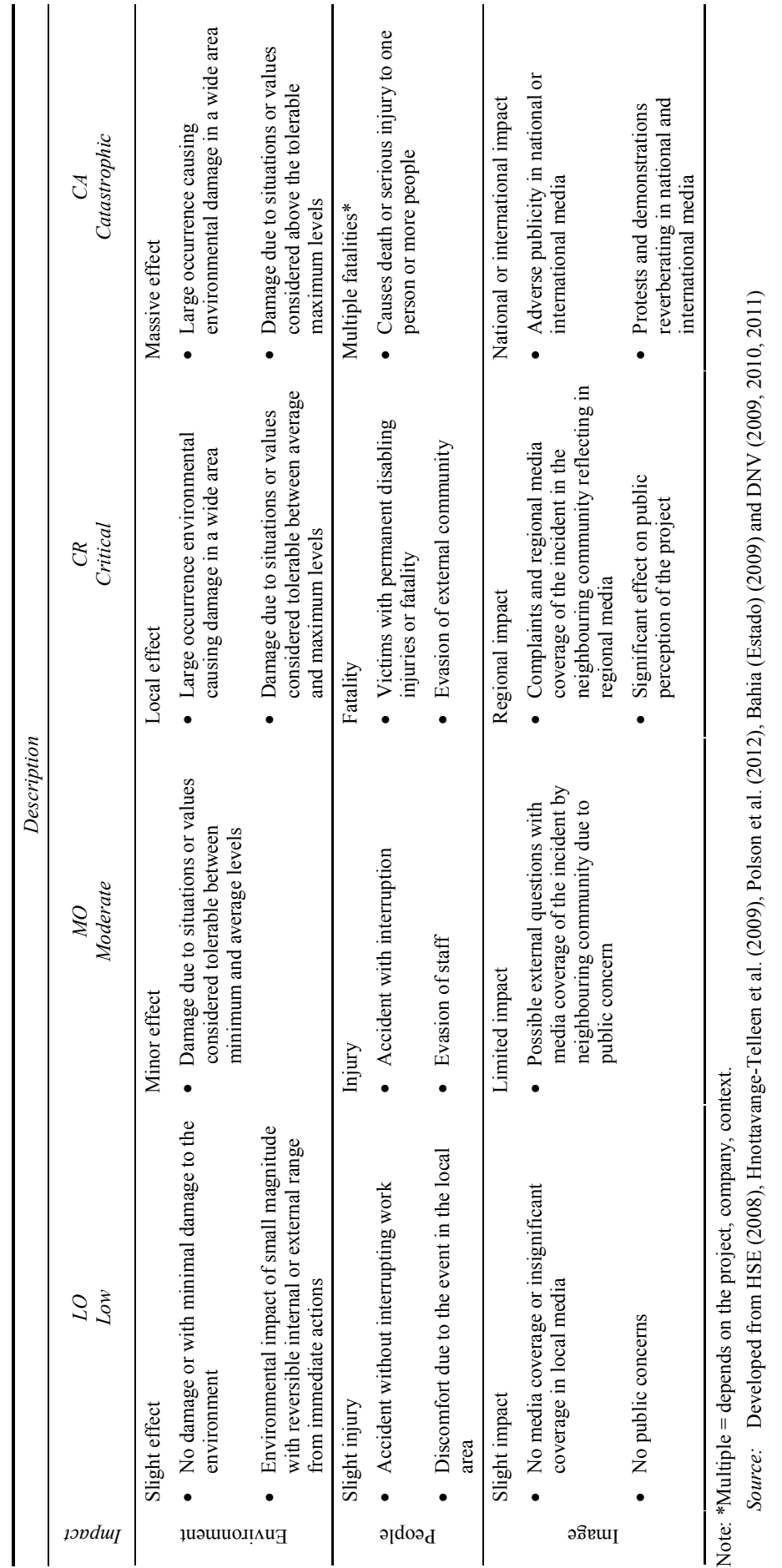


Table 6 Example of the severity categories for RA- $\mathrm{CO}_{2}$ method (continued)

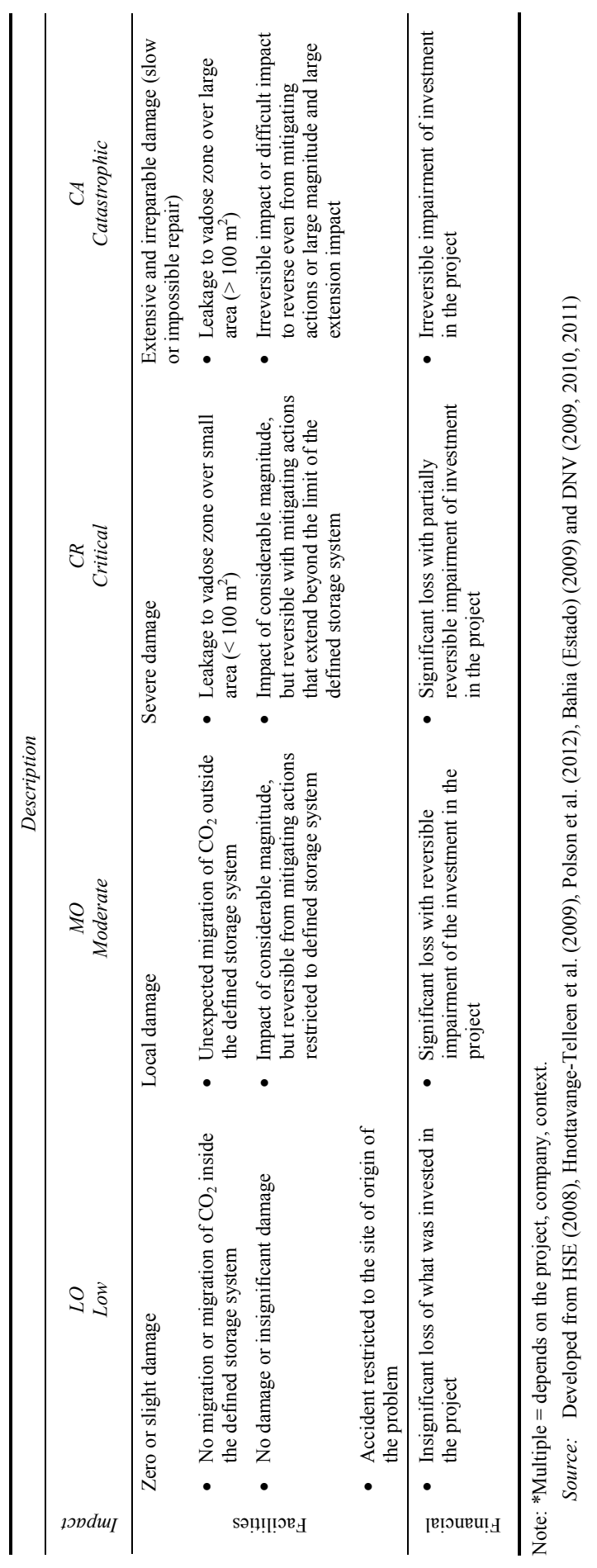


(7th column) risk: the classification of risks scenarios are shown in this column. The risks of scenarios are obtained by combining the frequency and severity categories from risk.

Matrix (Figure 4) and depending on the region, the risk can be classified as low, medium or high.

Figure 4 Example of risk classification matrix for the $\mathrm{RA}-\mathrm{CO}_{2}$ method

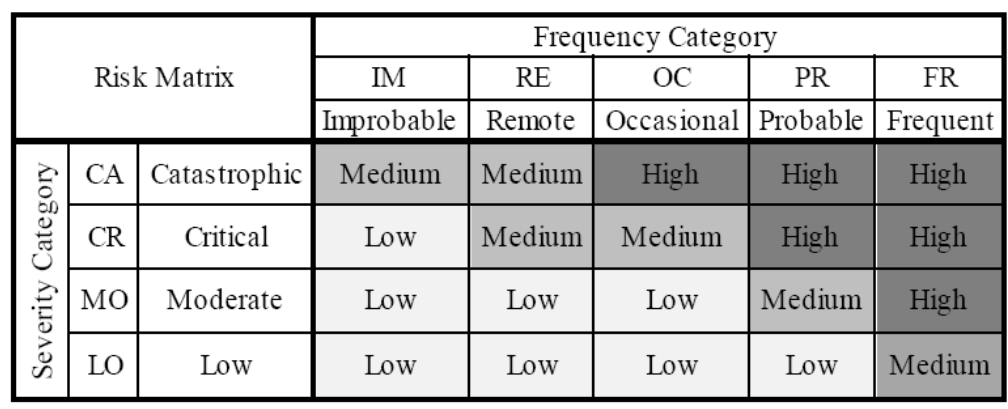

The risk obtained for each of the scenarios is associated with a qualitative uncertainty level, and this level is obtained from the values stipulated by the team for the both frequency and consequence information. For the scenarios that present uncertainty greater than $50 \%$, the team should propose measures to reduce the uncertainty.

According to CCPS-AICHE (2008), the risk acceptability criteria using Risk Matrix are the best metrics to determine if additional risk controls will be needed as well as the means to compare the benefits of competing risk mitigation options. In essence, Eduljee (2000) argues that the acceptability and development of risk management strategies is more likely to be based on the principles of as low as reasonably achievable (ALARA) or as low as reasonably practicable (ALARP) than on absolute expressions of risk or tolerability. To analyse these kinds of scenarios the team should evaluate based on a cost benefit decision. According to Nolan (1994), in cases where the cost for any proposed recommendation is near or exceeds the potential remediation costs after the potential incident, the risk may be termed as low as reasonably practical (ALARP). Based on Bahia (Estado) (2009), the risk criteria adopted this paper are the following:

High risk: this category indicates a condition of unacceptable risk, where it is necessary to propose measures to reduce risk that should be implemented on a mandatory and immediate basis as well as do a quantitative risk analysis.

Medium risk: this category indicates a condition of intermediate risk in which it is necessary to propose recommendations and corrective actions. The recommendations and corrective actions need to be presented as well as their respective deadlines for implementation. The implementation of the measures should take place if they are considered economically and technically feasible. The risk scenarios classified as medium risk should be subject to further analysis to reduce the risk and uncertainty analysis. After this, having exhausted the possibilities of improvements, they may be considered as acceptable though be still classified as medium risk. Thus, the most appropriate safeguard depends on a balance among cost, effort, and the benefits with implementing the improvements and the decision should take into consideration if the treatment of risk is economically justifiable. 
Low risk: this category indicates a condition of acceptable risk, in which recommendations can be considered as suggestions for reduced frequency or severity, and complementary studies are not necessary. Although the suggestions, comments and improvement actions can be proposed, implementation is not mandatory.

(8th column) actions and observations: in this column the observations, suggestions and actions needed for each accident scenario are listed.

(9th column) this column gives a serial number referencing each accident scenario to facilitate its identification.

\section{Conclusions}

Several alternatives have been studied to evaluate and understand the potential risks associated with $\mathrm{CO}_{2}$ geological storage. In spite of this, there are gaps in the methods evaluated. The main gaps identified for GS projects are related to uncertainty and frequency. These gaps have been caused mainly by lack of knowledge and lack of specific data about storage systems.

Among the seven methods for qualitative risk analysis, the SWIFT method was the most complete because the points discussed for each hazard identified causes, uncertainty, consequences and safeguards. From this comparative study, it was concluded that there is space to develop a user-friendly method applicable to complex and dynamic systems and that includes aspects, which influence risk estimation such as: uncertainty, safeguards, initiating event or causes, frequency and severity. Accordingly, the RA-CO method includes these characteristics.

With the implementation of the $\mathrm{RA}-\mathrm{CO}_{2}$ method to assess the risk associated to storage, it is possible to obtain information about the causes that lead to the unwanted migration of $\mathrm{CO}_{2}$ and the aggravating conditions that lead to this migration and preventive actions to avoid potential negative impacts as well their mitigating conditions. Thus, with the RA- $\mathrm{CO}_{2}$ method it is possible better understand the potential risks associated with the $\mathrm{CO}_{2}$ geological storage.

The economic cost comparison among the application of the RA-CO $\mathrm{CO}_{2}$ method and the other methods was not part of the scope of this paper since the identification of the main parameters that influence the application cost was not the subject of this work analysis. Some of the parameters are human resources availability, staff expertise, speed of data collection and maintenance cost of the organisational assets. Thus, according to demand, resources availability, assumptions, constraints, and technical requirements of the project, the use of methods can have complementary action or be more appropriate in a specific phase of CGS project.

The methods studied are all qualitative and they tend to have similar costs, which depend on the scale and complexity of the project. Thus, the focus of this work was not the identification of the application cost of the method, but the identification and implementation of actions that could improve the process. The use of $\mathrm{RA}-\mathrm{CO}_{2}$ method has the advantage of early recognition of the hazards involved in the process resulting in a cost saving method. Noteworthy that the mapping of uncertainty enables focus on future investment on the recommendations made for the scenarios with lower uncertainty.

In future studies the validation of the proposed $\mathrm{RA}-\mathrm{CO}_{2}$ method is planned using a real case study to evaluate how flexible, practical and systematic it can be. The RA-CO method can be applied to estimate the typical field risk for storage in a system that 
simulates the actual conditions for geological storage of carbon. For better comparison of costs among all the qualitative methods studied, it is recommended, for future work, the application of all the methods in the same project to assess the actual cost according to CGS project phases.

\section{Acknowledgements}

We are grateful to Centre of Excellence in Research in Carbon Storage (CEPAC) Teamwork and UNIFACS Laureate International Universities for permission to carry out part of the research in their facilities, and the collaboration of the Osvaldo Andrade Souza (DNV Consultant). The authors would like to thank FAPESB for supporting this research.

\section{References}

Australian Standards (2004) Risk Management Guidelines: Companion to AS/NZS4360: 2004, p.131, Standards Australia, Homebush, NSW.

Bachu, S. (2000) 'Sequestration of $\mathrm{CO}_{2}$ in geological media: criteria and approach for site selection in response to climate change', Energy Conversion \& Management, Vol. 41, No. 9, pp.953-970.

Bahia (Estado) (2009) Resolução Conselho Estadual do Meio Ambiente (CEPRAM), No. 3.965, art $1^{\circ}$, de 30 de Junho de 2009, Aprova a Norma Técnica NT-01/2009 e seus Anexos, que dispõe sobre o Gerenciamento de Risco no Estado da Bahia. Diário Oficial do Estado, Bahia, 11 ago, 2009m No. 20.053.

Benson, S. (2005) 'Risk assessment preface', in Benson, S. (Ed.): Carbon Dioxide Capture for Storage in Deep Geologic Formations - Results from the $\mathrm{CO}_{2}$ Capture Project: Geologic Storage of Carbon Dioxide with Monitoring and Verification, Vol. 2, Elsevier, London.

Benson, S. (2008) 'Multi-phase flow and trapping of $\mathrm{CO}_{2}$ in Saline Aquifers', Published in the Proceedings of 2008 Offshore Technology Conference, Houston, TX, USA, 5-8 May 2008, Paper No. OTC 19244.

Benson, S. and Hepple, R. (2005) 'Prospects for early detection and options for remediation of leakage from CO2 storage projects', in Benson, S. (Ed.): Carbon Dioxide Capture for Storage in Deep Geologic Formations - Results from the $\mathrm{CO}_{2}$ Capture Project: Geologic Storage of Carbon Dioxide with Monitoring and Verification, Vol. 2, No. 28, pp.1189-1203, Elsevier, London.

Bowden, A., Pershke, D. and Chalaturnyk, R. (2013a) 'Geosphere risk assessment conducted for the IEAGHG Weyburn-Midale $\mathrm{CO}_{2}$ monitoring and storage project', International Journal of Greenhouse Gas Control, Vol. 16S, Supplement 1, pp.S276-S290.

Bowden, A., Pershke, D. and Chalaturnyk, R. (2013b) 'Biosphere risk assessment for $\mathrm{CO}_{2}$ storage projects', International Journal of Greenhouse Gas Control, Vol. 16S, Supplement 1, pp.S291-S308.

Bradshaw, J. et al. (2007) ' $\mathrm{CO}_{2}$ storage capacity estimation: issues and development of standards', International Journal of Greenhouse Gas Control, Vol. 1, No. 1, pp.62-68.

Carbon Sequestration Leadership Forum (CSLF) (2009) Phase I Final Report from CSLF Risk Assessment Task Force, Report CSLF-T-2009-04 [online] http://www.cslforum.org/ publications/documents/RATF_Phase1FinalReport.pdf (accessed 20 July 2013).

Center for Chemical Process Safety-American Institute of Chemical Engineers (CCPS-AICHE) (2008) Guidelines for Chemical Transportation Safety, Security, and Risk Management, Wiley, New York. 
Cherkaoui, A. and Lopez, P. (2009) ' $\mathrm{CO}_{2}$ storage risk assessment: feasibility study of the systemic method MOSAR', Safety and Security Engineering III (WIT Transactions on the Built Environment), Vol. 108, pp.173-184.

Choi, Y. et al. (2013) 'Wellbore integrity and corrosion of carbon steel in $\mathrm{CO}_{2}$ geologic storage environments: a literature review', International Journal of Greenhouse Gas Control, Vol. 16S, Supplement 1, pp.S70-S77.

Condor, J. et al. (2011) 'A comparative analysis of risk assessment methodologies for the geologic storage of carbon dioxide', Energy Procedia, Vol. 4, pp.4036-4043.

Det Norske Veritas (DNV) (2009) $\mathrm{CO}_{2}$ QUALSTORE: Guideline for Selection and Qualification of Sites and Projects for Geological Storage of $\mathrm{CO}_{2}$, Report No. 2009-1425, Norway [online] http://www.dnv.com/binaries/co2qualstore_guideline_tcm4-412142.pdf (accessed 20 May 2013).

Det Norske Veritas (DNV) (2010) $\mathrm{CO}_{2}$ QUALSTORE: Workbook with Examples of Applications, Report No. 2010-0254, Norway [online] http://www.dnv.com/binaries/co2qualstore workbook_tcm4-436659.pdf (accessed 13 May 2013).

Det Norske Veritas (DNV) (2011) CO2WELLS: Guideline for the Risk Management of Existing Wells at $\mathrm{CO}_{2}$ Geological Storage Sites, Report No. 2011-0448, Norway [online] $\mathrm{http}: / / w w w . d n v . c o m / b i n a r i e s / c o 2 w e l l s \_g u i d e l i n e \_t c m 4-465269 . p d f(a c c e s s e d 13$ May 2013).

Eduljee, G. (2000) 'Trends in risk assessment and risk management', The Science of the Total Environment, Vol. 249, Nos. 1-3, pp.13-23.

Einsiedel, E.E. et al. (2013) 'Assessing socio-technical mindsets: public deliberations on carbon capture and storage in the context of energy sources and climate change', Energy Policy, Vol. 53, pp.149-158.

Engebø, A. et al. (2013) 'Risk assessment and management for $\mathrm{CO}_{2}$ capture and transport facilities', Energy Procedia, Vol. 37, pp.2783-2793.

Environmental Protection Agency (EPA) (2008) Vulnerability Evaluation Framework for Geologic Sequestration of Carbon Dioxide, EPA430-R-08-009, p.85.

Fletcher, W. (2005) 'The application of qualitative risk assessment methodology to prioritise issues for fisheries management', ICES Journal of Marine Science, Vol. 62, No. 8, pp.1576-1587.

Frailey, S. and Finley, R. (2009) 'Classification of $\mathrm{CO}_{2}$ geologic storage: resource and capacity', Energy Procedia, Vol. 1, No. 1, pp.2623-2630.

Fundação Estadual de Proteção Ambiental Henrique Luiz Roessler (FEPAM) (2001) Manual de Análise de Riscos Industriais, Projeto de Manual de Análise FEPAM nº 01/01, Rio Grande do Sul: FEPAM.

Gerard, D. and Wilson, E. (2009) 'Environmental bonds and the challenge of long-term carbon sequestration', Journal of Environmental Management, Vol. 90, No. 2, pp.1097-1105.

Gough, C. and Shackley, S. (2006) 'Towards a multi-criteria methodology for assessment of geological carbon storage options', Climate Change, Vols. 1-3 No. 74, pp.141-174, Manchester.

Health Service Executive (HSE) (2008) Risk Assessment Tool and Guidance: Including Guidance on Application.

Hnottavange-Telleen, K., Krapac, I. and Vivalda, C. (2009) 'Illinois Basin - Decatur project: initial risk-assessment results and framework for evaluating site performance', Energy Procedia, Vol. 1, No. 1, pp.2431-2438.

Intergovernmental Panel on Climate Change (IPCC) (2005) IPCC Special Report on Carbon Dioxide Capture and Storage, Cambridge University Press, Cambridge.

Intergovernmental Panel on Climate Change (IPCC) (2007) Climate Change 2007: Synthesis Report, Geneva, Switzerland.

International Energy Agency Greenhouse Gas R\&D Programme (IEAGHG) (2009) Natural and Industrial Analogues for Geological Storage of Carbon Dioxide. 
International Organization for Standardization (I SO) 31000 (2009) ISO 31000:2009: Risk Management: Principles and Guidelines, Switzerland.

Johnsson, F. et al. (2010) 'Stakeholder attitudes on carbon capture and storage - an international comparison', International Journal of Greenhouse Gas Control, Vol. 4, No. 2, pp.410-418.

Kaplan, S. and Garrick, B. (1981) 'On the quantitative definition of risk', Society for Risk Analysis, Vol. 1, No. 1, pp.11-27.

Kempka, T. et al. (2013) 'Assessment of long-term $\mathrm{CO}_{2}$ trapping mechanisms at the Ketzin pilot site (Germany) by coupled numerical modelling', Energy Procedia, Vol. 37, pp.5419-5426.

Koornneef, J. et al. (2012) 'The environmental impact and risk assessment of $\mathrm{CO}_{2}$ capture, transport and storage e an evaluation of the knowledge base', Progress in Energy and Combustion Science, Vol. 38, No. 1, pp.62-86.

Leitch, M. (2010) 'ISO 31000:2009 - the new international standard on risk management', Risk Analysis, Vol. 30, No. 6, pp.887-892.

Morgado, C. and Esteves, V. (2011) 'Technological challenges in risk management of carbon capture and geological storage (CCGS) projects', Proceedings of the International Conference on Industrial Engineering and Operations Management, 22-25 January, Kuala Lumpur, Malaysia.

National Energy Technology Laboratory (NETL) (2013) Best Practices for: Risk Analysis and Simulation for Geologic Storage of $\mathrm{CO}_{2}$, p.86, Report DOE/NETL-2013/1603.

Nolan, D. (1994) Application of HAZOP and What-if Safety Reviews to the Petroleum, Petrochemical and Chemical Industries, 1st ed., Noyes Publications, New Jersey.

Oldenburg, C. (2008) 'Screening and ranking framework (SRF) for geologic $\mathrm{CO}_{2}$ storage site selection on the basis of HSE risk', Environmental Geology, Vol. 54, No. 8, pp.1687-1694.

Pacala, S. and Socolow, R. (2004) 'Stabilization wedges: solving the climate problem for the next 50 years with current technologies', Science, Vol. 305, No. 5686, pp.968-972.

Paltrinieri, N. et al. (2013) 'Identification of hazards and environmental impact assessment for an integrated approach to emerging risks of $\mathrm{CO}_{2}$ capture installations', Energy Procedia, Vol. 37, pp.2811-2818.

Paraguassu, M. (2012) Method Proposed for Qualitative Risks Assessment for the Carbon Dioxide Geological Storage: A Case Study of the Fazenda Mamoeiro Field Situated in Reconcavo Basin, Unpublished Master thesis (Master of Industrial Engineering), Federal University of Bahia, Salvador, Brazil.

Paté-Cornell, M. (1996) 'Uncertainties in risk analysis: six levels of treatment', Reliability Engineering and System Safety, Vol. 54, Nos. 2-3, pp.95-111.

Polson, D., Curtis, A. and Vivalda, C. (2012) 'The evolving perception of risk during reservoir evaluation projects for geological storage of $\mathrm{CO}_{2}$ ', International Journal of Greenhouse Gas Control, Vol. 9, pp.10-23.

Praetorius, B. and Schumacher, K. (2009) 'Greenhouse gas mitigation in a carbon constrained world: the role of carbon capture and storage', Energy Policy, Vol. 37, No. 12, pp.5081-5093.

Purdy, G. (2010) 'ISO 31000:2009 - setting a new standard for risk management', Risk Analysis, Vol. 30, No. 6, pp.881-886.

Quintessa (2010) Generic $\mathrm{CO}_{2}$ FEP Database, Version 1.1.0, Quintessa Limited, Henley-on-Thames, UK [online] http://www.quintessa.org/co2fepdb (accessed 20 July 2013).

Roberts, J., Wood, R. and Haszeldine, R. (2011) 'Assessing the health risks of natural $\mathrm{CO}_{2}$ seeps in Italy', PNAS, Vol. 108, No. 40, pp.16545-16548.

Savage, D. and Maul, P. (2004) A Generic FEP Database for the Assessment of Long-Term Performance and Safety of the Geological STORAGE of $\mathrm{CO}_{2}$, Version 1.0, QRS-1060A-1, Quintessa.

Sollie, O. et al. (2011) 'An early phase risk and uncertainty assessment method for $\mathrm{CO}_{2}$ geological storage sites', Energy Procedia, Vol. 4, pp.4132-4139. 
Song, J. and Zhang, D. (2013) 'Comprehensive review of Caprock-Sealing mechanisms for geologic carbon sequestration', Environmental Science \& Technology, Vol. 47, No. 1, pp.9-22.

Sutton, I. (1997) Process Safety Management, 2nd ed., MP - Morris Publishing, Houston, USA.

Szulczewski, M. et al. (2012) 'Lifetime of carbon capture and storage as a climate-change mitigation technology', PNAS, Vol. 109, No. 14, pp.5185-5189.

Tucker, O. et al. (2013) 'Development of an offshore monitoring plan for a commercial $\mathrm{CO}_{2}$ storage pilot', Energy Procedia, Vol. 37, pp.4317-4335.

Underschultz, J. et al (2011) ' $\mathrm{CO}_{2}$ storage in a depleted gas field: An overview of the $\mathrm{CO}_{2} \mathrm{CRC}$ Otway Project and initial results', International Journal of Greenhouse Gas Control, Vol. 5, No. 4, pp.922-932.

Viebahn, P. et al (2007) 'Comparison of carbon capture and storage with renewable energy technologies regarding structural, economic, and ecological aspects in Germany', International Journal of Greenhouse Gas Control, Vol. 1, No. 1, pp.121-133.

Wildenborg, T. et al. (2005) 'Risk assessment methodology for $\mathrm{CO}_{2}$ storage: the scenario approach', in Benson, S. (Ed.): Carbon Dioxide Capture for Storage in Deep Geologic Formations - Results from the $\mathrm{CO}_{2}$ Capture Project: Geologic Storage of Carbon Dioxide with Monitoring and Verification, Vol. 2, pp.1293-1316, Elsevier, London.

Wu, D. and Olson, D. (2009) 'Introduction to the special section on 'optimizing risk Management: methods and tools', Human and Ecological Risk Assessment: An International Journal, Vol. 15, No. 2, pp.220-226.

Wu, D. and Olson, D. (2010) 'Introduction to special section on 'risk and technology', Technology Forecasting and Social Change, Vol. 77, No. 6, pp.837-839.

Wu, D., Olson, D. and Birge, J. (2013) 'Risk management in cleaner production', Journal of Cleaner Production, Vol. 53, pp.1-6.

Yavuz, F. et al. (2009) 'Second generation $\mathrm{CO}_{2}$ FEP analysis: CASSIF - carbon storage scenario identification framework', Energy Procedia, Vol. 1, No. 1, pp.2479-2485.

\section{Notes}

1 Carbon Sequestration Leadership Forum.

2 Environmental Protection Agency. 